\title{
Flood causes, consequences, protection, measures and management in Kaserkand, Sarbaz and Dashtyari Districts, Makoran, Iran
}

\author{
Mohammad Anwar Zainudini 1, ${ }^{*}$ and Asadollah Sardarzaei 2 \\ ${ }^{1}$ Department of Oceanography, Faculty of Marine Sciences, Chabahar Maritime University, Iran. \\ 2 Department of Basic Science, Faculty of Marine Sciences, Chabahar Maritime University, Iran.
}

Global Journal of Engineering and Technology Advances, 2022, 10(02), 094-102

Publication history: Received on 20 December 2021; revised on 12 February 2022; accepted on 14 February 2022

Article DOI: https://doi.org/10.30574/gjeta.2022.10.2.0025

\begin{abstract}
Flooding is the most overwhelming natural hazard in this region due to miscellaneous ecosystems and occurs mainly due to the heavy monsoon rains throughout the country, commonly late in the summer season and overflow the rivers and streams over dry land. In the Makoran region floods are a common problem and their continuity makes them more alarming for its economic growth. Flooding is globally a major natural hazard and results in property and life loss and poor economic development. Though it is not possible to prevent the occurrence of floods, their negative impacts could be minimized substantially through proper planning and effective preparation. The susceptibility to floods could be reduced by accurate and timely prediction (Forecasting and Warning) and by impact-reducing measures. Although the impacts of floods vary from one place to another and in the consequences, there are significant losses such as human life lost their shelter, livelihood, damage to the public and private infrastructures such as roads and bridges. The aim of this work is to present a brief analysis of the flooding behavior of the Kajo and Sarbaz basin, flood causes, their dreadful impacts, and the flood administration at the national level. This study also examines the aftermaths of severe floods in the Makoran region by a comprehensive and systematic review of consequence, protection, measures and management with a suitable investigation. Recommendations have been made through detailed analysis of flooding, to minimize the terrible impacts and to avoid floods continuity in coming years. It could be managing with constructing storage dams, diversion canals, dikes and storm surge barriers.
\end{abstract}

Keywords: Disaster; Flood; Integrated flood; Risk management; Risk assessment; Vulnerability Floods

\section{Introduction}

Flooding is globally a major natural hazard which results in property and life loss and poor economic development. Though it is not possible to prevent the occurrence of floods, but their negative impacts could be minimized considerably, through proper planning and effective preparation. The vulnerability to floods could be reduced by accurate and timely prediction (Forecasting and Warning) and by impact-reducing measures. Makoran region is adversely affected and faces flooding problem almost every year in the recent past which cause's huge loss of infrastructure, life and land with poor management of water resources and lack of effective water policy have led to flooding problem [4]. It has been reported that among Middle Eastern and South Asian countries affected by flooding, Iran and Pakistan respectively are in first and fifth places. The historical perspective of floods and the nature and causes of floods in Makoran are portrayed below in figure 1.

Stream and rivers provide water for drinking, watering animals, irrigation and for human habitation for over thousands of years. They are dynamic environments and their banks are prone to erosion, and this is part of a river normal cycle that relied upon the generations of farmers for restocking and fertilizing their fields. However, the use of river

\footnotetext{
${ }^{*}$ Corresponding author: Mohammad Anwar Zainudini

Department of Oceanography, Faculty of Marine Sciences, Chahbar Maritime University, Iran.
} 
floodplains has changed dramatically in the past few decades [18]. Thousands of miles of earthen levees, flood walls, and river control structures have been built along both Rivers (Kajo and Sarbaz). Dikes and levees have been built around the two rivers in attempts to keep the flood waters out of villages. In the light of flood control modifications to dam or reservoir as outlined in alternatives are intended to support limited flood control operation at reservoir in both rivers in Makoran region. Furthermore, it could be anticipated that this flood control capacity would remain until a flood event occurs in that particular corresponding area [6]. During a flood event, out flows from the dam could be reduced in order to prevent flow of water at reservoirs, the flood water was uncontrollable because the Pishin dam does not have any levees or by pass canals or dykes to protect the dam from cracking or even from complete destruction. There could be several flood control strategies being analysed but commonly to modify operations reservoirs in the region which may require new outlets, increased storage and new discharge guidelines. The objective of this study is to provide the authority which is the main sponsors and other interested for water management some discussion of the potential environmental impacts associated with these proposed modifications and to provide some related recommendations and participations [11].
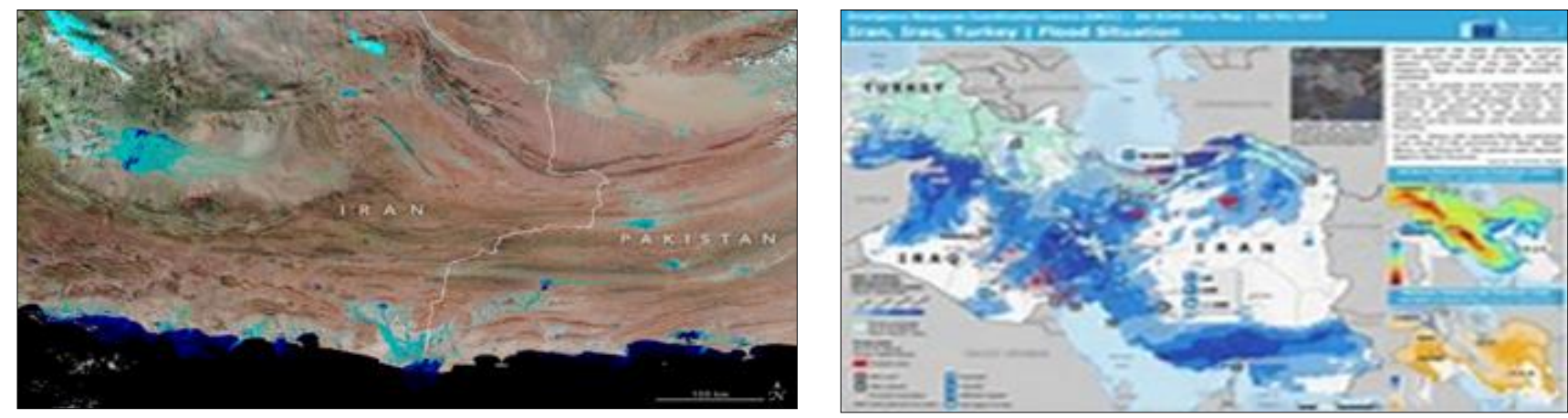

Figure 1 The area of study Rivers Kajo and Sarbaz in Makoran Region, Iran

The need to develop a re-operation plan based on the dam modification alternatives presented would be an integral part to the overall success towards flood control. Water discharge during flood 1997 and 2005, water resources authority released excess flood water without any consideration to downstream agricultural farms and villages which damaged many lives and farms land, in fact it was a deliberate mismanagement by the authority and also there is lack of any flood by pass or diversion canal to that particular area on the other hand there were also occurs drought because entire water released from Pishin dam and entire water kept in Zirdan dam which wasted by means of evaporation. Then in these two particular caes minimum water should be release from the reservoir and maximum water can be stored. As the reservoir rises and reaches each intake, the corresponding outflows adjust on a continuum with one outlet submerged then it could be possibility in the case of flooding all outlet perhaps would submerged, where after the reservoir fills, so discharge is passed both through the sluiceways and over the spillway (Figure (2) [21].

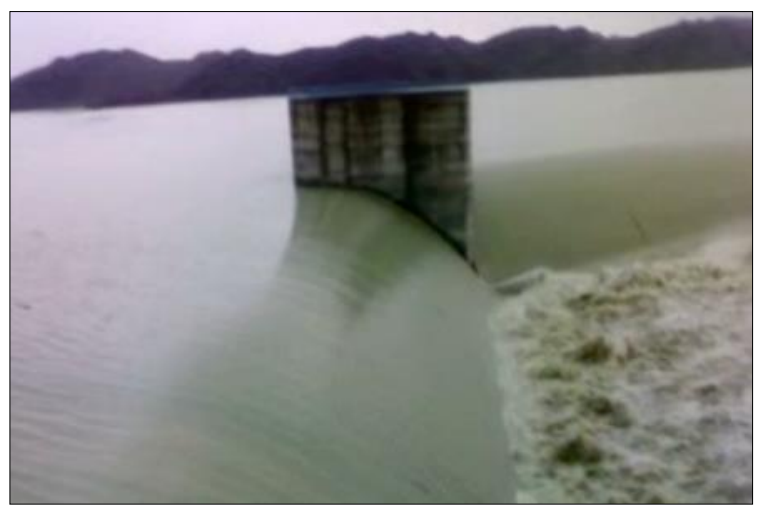

Figure 2 Spillway of the Pishin Dam with bankfull flow during flash flood in the stem of Sarbaz River 2020

\section{Material and methods}

The area of the study is near the border of Iran and Pakistan, extending south from Afghanistan to the Gulf of Oman. A location plan is shown in Figure 1 data for in this paper has been obtained from the Water Resources Department of the 
Islamic Republic of Iran Meteorological Organisation (IRIMO), and relates to the Province of Sistan and Balochistan. It is noted that there is also a neighbouring Province of Balochistan to the west in Pakistan. The climate of the region varies from subtropical arid and semi-arid to temperate sub-humid in the plains of Sistan and Balochistan. The rainfall data studied in this paper comes from the southern part of the region, including the port of Chahbahar [10]. Therefore, flash flood disasters occurred in Gasrghand and Dashtyari districts on cities like: Koshok, Omeri , Sedikzahi, Oraki, Haji Abad and Bohokalat, Tokal and Loryani on 20/7/ 2020 which is illustrated in figure (3).
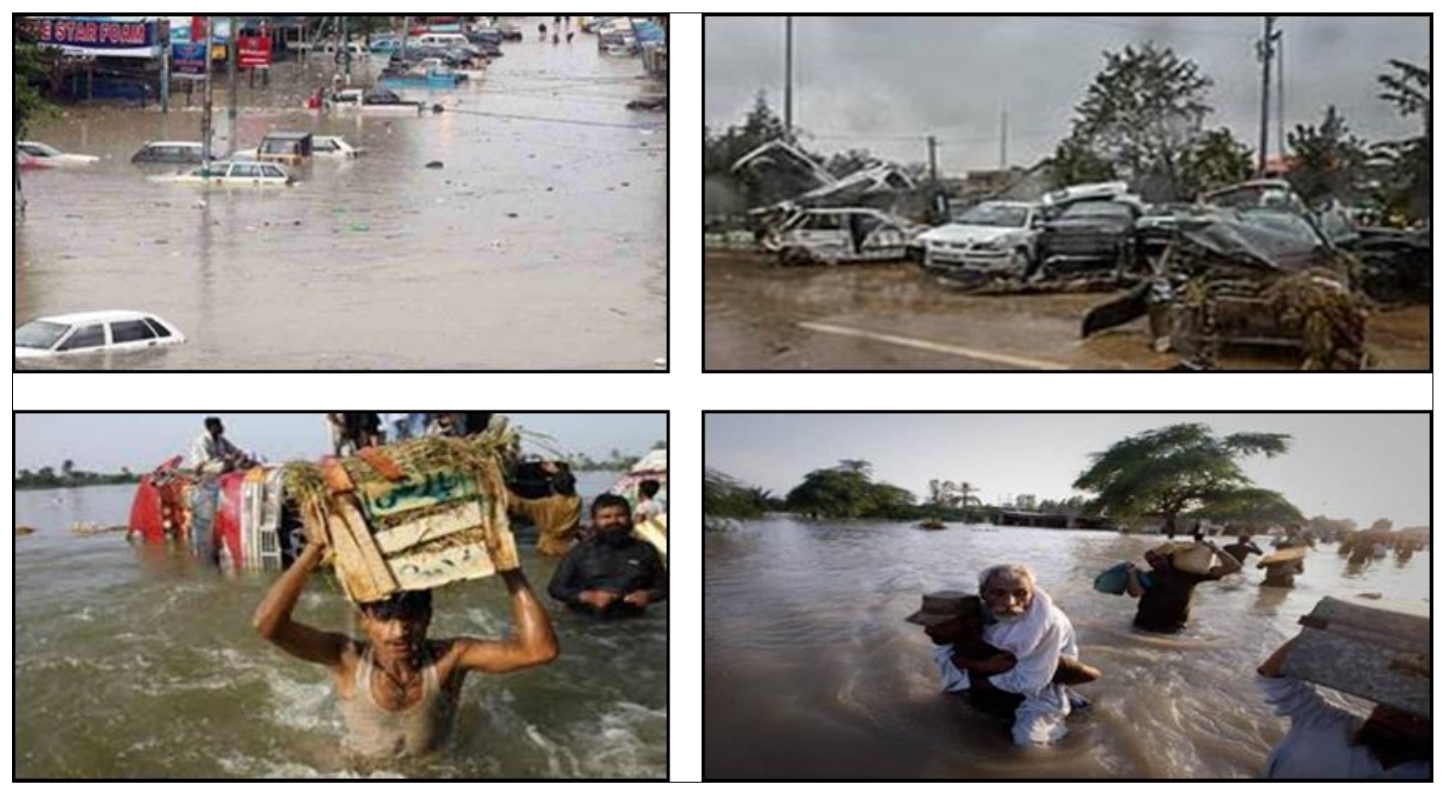

Figure 3 Illustrates human effects on riverine flood risk disasters, river Kajoo and Sarbaz, overtopped levee during the flash flood in July 2020

The study was conducted at Zirdan Dam in Dashtyari. Thus location up on which this study concentrates is bounded by the coastline of southern Iran and Western of Pakistan, approximately, by the line of latitude 25 degree to the South and the line of longitude 60 degree to the west. The area consists of an inland chain of steeply sloping bare rock (mountains) which drain onto a coastal alluvial plain. The analysis is based on a multi-sites analysis approach, since the two rivers locations are not considered sufficiently similar to be pooled together. The study area might be classified as "Tropical Triple season Moderate Climate Zone", which is characterized by single rainfall season from July-September and its moderating influence in temperature. The river flow and rainfall temperature pattern of the area based on the record of data obtained from Iran Meteorological and water resources organization department [8].

The flow data was obtained from 12 months from January to December has been tested by computer excel program the peak discharge was ranging from $3879 \mathrm{~m}^{3} / \mathrm{sec}$ the same river on the month of April suddenly rate of flow dropped to 6 $\mathrm{m}^{3} / \mathrm{sec}$ even though for other months during summer rate of flow for Kajo river is completely drought or nil discharge according to the dry months when there is no rainfall at all in Makoran region [9].

\subsection{Natural and Physical Environment of Makoran}

In Makoran, the flood study could be said with location of Sarbaz and Kajo rivers the upstream parts of the rivers flow through heavily mountainous and hilly regions while the remainder of rivers flows through broad, flat valleys. The upland, villages landscapes are dominated by a mixed area, which areas comprised of Nannorrhops (Mazari palm trees) and tamarixesetc [14]. Also the upstream half of the rivers below Pishin and Zirdan flood control dams are dominated by coarse gravels, with areas of fines and larger sands also present to a lesser degrees. The downstream half of both rivers below the dams are predominately small to medium sized sand or cobbles. Therefore, interspersed with areas of fine sediment and larger sands and boulders, the coarse gravels are also present in those particular areas. Furthermore, the historic water quality problems stemmed from drainage and rainfall runoff, which also caused low dissolved oxygen, elevated water temperatures and high turbidity. Low summer flows have also caused some problems in the river but these are primarily a natural function arising from the small drainage size. Although, there are many reaches existed, so the majority of reaches are located of the side of the rivers. However urban development along these rivers in Makoran is important feature, providing crucial life history for flood control and also for such as rearing and holding habitat for 
fish, and over wintering habitat for migrating waterfowl. The existing fill and spill for flood control dams operations result in seasonal fluctuations surface elevations [15].

\subsection{Flood Management Current State and Flood Policy Strategy}

Iran current flood management system consists of flood policy and strategy, flood laws, flood institutions, flood planning and flood management measures. These elements of flood management system are described below. The development and implementation of flood policy by government reflects a serious commitment of government towards effective and sustainable flood management. In Iran, flood management policy has been recognized in the draft national water policy, these policies just copied from advanced European countries or The United Sates, which has not been approved and implemented yet. The main elements of flood policy include: "development of new water storages, improvement of operational rules for reservoirs, improved watershed management, promotion of flood retardation structures, improved maintenance of existing flood infrastructure, improved flood forecasting and warning system, enforcement of laws for flood plains protection and flood zoning" [8]. The flood strategy is implemented through deployment of structural and non-structural measures, in Iran, the current flood management strategy consists of four elements, namely:

- $\quad$ Flood planning

- $\quad$ Flood preparedness

- $\quad$ Flood fighting

- $\quad$ Post-flood operations

\subsection{Potential impact of climate change on the intensity and frequency of flood events}

While the evidence is far from conclusive, climate change is expected to impact the nature of flood risk going forward as a result of changes to:

- The frequency of heavy precipitation events

- The range and intensity of cyclones

- $\quad$ The rise in sea-levels [1].

Specifically, in their special report on Managing the risks of extreme events and disasters to advance climate change adaptation (2014), the Inter-Governmental Panel on Climate Change (IPCC) found evidence of a number of likely impacts of climate change on the nature of flood events (although subject to significant regional variation and various levels of uncertainty), including:

- The frequency of heavy precipitation or the proportion of total rainfall from heavy rainfalls will likely increase over many areas of the globe as higher air temperatures allow the atmosphere to retain more water.

- The average tropical cyclone maximum wind speed will likely increase in some ocean basins.

- $\quad$ There may be a projected pole ward shift of extra tropical storm tracks.

- The mean sea level rise will very likely contribute to upward trends in extreme coastal high water levels.

- Changes in heat waves, glacial retreat, and/or permafrost degradation will affect high mountain phenomena such as slope instabilities, movements of mass, and glacial lake outburst floods [4].

Among these potential impacts, the IPCC places more confidence in the predicted impact on rainfall intensities than other natural disasters (IPCC, 2012). An increase in the occurrence of heavy precipitation events could increase the frequency of flash floods, riverine floods and groundwater floods. Increasing levels of urbanization, which will generally reduce the water absorption capacity of land by converting natural terrain to urban use, will likely exacerbate these climate change impacts and increase the level of resulting damage. While there is significant uncertainty in assessing the potential implications of climate change on flood risk, a number of studies have analysed this issue. For example, an assessment of likely changes in river flooding return periods found that the frequency of river flooding will likely double (or more) by 2050 (relative to the period 1991-2020) in Central and Eastern Asia, and some parts of Western and Central Africa - while decreases in frequency can be expected in some parts of Asia [1]. Based on the projections of numerous climate models, the return periods for what are currently considered 1-in-100 year floods is expected to decline (i.e. occur more frequently) by 2100 in 22 of the 29 major river basins examined, and decline significantly in a number of basins including the Damen river. Close to $90 \%$ of the respondents to questionnaire on the financial management of flood risk indicated that climate change has increased the level of flood risk in the country, with almost $50 \%$ indicating that that impact has already been significant [2]. A number of studies have used climate change scenarios to model the possible impacts of climate change on flood losses for different regions of the world (for various time 
periods), using a range of approaches to estimating the damage that could occur as a Sea-level rise, which is also predicted with a higher-level of confidence, increases the risk of coastal flooding. A study of communities along the Asia particularly Oman and Persian Gulf coasts found that, even under a mid-range scenario for future sea level rise, twothirds of communities could face an increase in the frequency of high-tide flooding (i.e. tidal flooding under normal (non-storm) conditions) of 300\% from current levels, with a number of communities facing regular extensive flooding from high-tides alone [3].

\subsection{Investments in risk reduction}

Investments in prevention to lower the probability of a flood event occurring or in mitigation to reduce the losses resulting from a flood event is a critical element in the financial management of flood risk. Such investments can also be particularly effective in the case of floods relative to other natural disaster risks given the greater ability to protect communities and structures from water penetration through land-use planning, structural mitigation investments and household mitigation investments [7]. The types of prevention and mitigation investments can be grouped into three main categories:

- $\quad$ land-use planning and restrictions aimed at reducing the level of assets exposed to flood risk or reducing the impact of flooding through the use of natural mitigation measures (e.g. wetlands, mangroves);

- $\quad$ community structural flood mitigation measures (e.g. flood defenses, drainage systems) aimed at protecting particular areas against inundation; and

- $\quad$ risk reduction at the level of individual properties (e.g. elevating a property).

These types of investments are not mutually exclusive and should all be considered as part of a comprehensive approach to flood prevention and mitigation. Analyses of the potential benefits of risk reduction in terms of reducing future losses have generally shown that risk reduction measures can create substantial benefits. The US Federal Emergency Management Agency has estimated, based on a review of 4000 risk reduction programs, that the average cost-benefit ratio for investments in risk reduction is 1:4 (i.e. the benefits from risk reduction projects are 4 times the cost) [5 ]. In the United Kingdom, the Environment Agency estimates that its capital investment in the flood and coastal erosion sector can achieve a whole life cost-benefit ratio of 1:9 or higher (Environment Agency, 2014).

\subsection{Structural flood mitigation}

Structural flood mitigation measures, such as dams, levees and reservoirs as well as natural mitigation approaches such as the re-forestation of drainage basins, may be used to reduce flood risk by protecting areas from a given level of inundation and therefore reducing the frequency of flooding. Such measures may be the only cost effective approach to reducing flood risk in built-up areas located in floodplains [11]. Improvements to urban drainage systems as well as the installation of permeable pavement (which is mandatory in the Iran) can also be effective in improving water absorption capacity in urban areas. For example, improvements to the urban drainage systems in Mumbai could potentially reduce direct and indirect losses from a 100-year flood by 70\% [16]. Due to the size of the investment needed, large structural mitigation investments tend to be most cost effective where the value of assets protected is also very high (such as urban areas) (i.e. the benefits in terms of avoided losses justify the large cost of investment). In many major cities, including Shiraz, Mazendran and Karaj, flood protection levels of 50- years or more have been established or are under development [15].

\subsection{Enhancing public awareness and Building understanding of risk levels}

There are a number of opportunities to enhance public awareness of the level of risk from flooding, ranging from making information on flood risk widely available to disclosure requirements related to property transfer or rental, to the use of price signals in setting insurance premiums. Almost all countries make information on flood risk publicly available. More than two-thirds of countries that responded to an OECD survey indicated that flood hazard maps are made publicly available and that various types of awareness campaigns are implemented to enhance understanding of flood risk [25]. For example, in Japan, the Flood Control Act requires municipalities to distribute relevant information on flood risk to residents. In the United States, the Flood Smart program provides information on flooding and flood risk. In the United Kingdom, the "What's in your backyard" application allows users to access flood risk (and other environmental) information at the post code level. In France, a major public awareness campaign surrounded a major flood exercise for a 1-in-100 year flood affecting the Paris region, including videos of the potential impacts of flooding on various Paris landmarks [24]. In Australia, a National Flood Risk Information Project has been implemented to improve the quality, availability and accessibility of flood risk information, flood hazard data and flood-related imagery (including from past events). However, concerns about liability related to the accuracy of flood risk information have led to some reluctance to publishing all relevant information (similar to the liability concerns related to land-use planning [20]. 
A significant opportunity to build awareness arises at the time of purchase or rental of a residence and, in some countries, information on flood (and other hazards) at the level of individual properties is communicated at that time. For example, in France, sellers and landlords are required to provide information on any compensation that has been paid in relation to the property as a result of a natural (or technological) disaster and the risk of flooding must be disclosed as part of the home purchase process [23]. Such information is also available in Iran (as "vendor statements") with some states (e.g. Gillan) deemed to be providing a robust system of disclosure of flood and other natural hazard risks (Productivity Commission, 2014). In other countries, property-level risk information is available but is not automatically disclosed upon property transfer or rental [21]. In Iran, a Land Information Memoranda that provides information on natural hazard risks associated with a property or structure is available from the local council to any party upon request and payment of a fee. In Makoran, the Environment Agency and Natural Resources of Balochistan can provide households with a detailed flood map or a letter setting out the flood risk from rivers and the sea for the area of their property which can be used for the purposes of securing insurance coverage [25]. There is some evidence that public awareness levels will be affected by the approach taken to communicating risk. For example, a 1-in-5 chance of a flood over 25 years. There is some evidence that public awareness levels will be affected by the approach taken to communicating risk. For example, a 1-in-5 chance of a flood over 25 years has been demonstrated to be taken more seriously than a 1-in-100 chance of a flood on an annual basis, even though the two describe similar levels of risk $(0.8 \%$ annual probability vs. $1.0 \%$ annual probability). The use of return period probability measures (i.e. 1 in a given number of years) may give some the mistaken impression after an event that they will be safe from flooding for the remainder.

\section{Results and discussion}

Both discharge data from stream gauge stations and from post-flood analysis were available in the study. Discharge data from stream gauge stations were available for two cases, whereas data from post-flood analysis were used in the remaining four cases. Post-event analysis methods include a range of procedures for indirect estimation of peak discharges, generally encompassing the following steps: identification of the flow process (which was categorized into the following classes: 1- liquid flow 2- hyper concentrated flow 3- debris flow), high water marks identification, postflood river geometry survey, and application of appropriate hydraulic methods for peak flood computation [8]. With regard to the classification of the flow process, only liquid flows were considered in this study. Together with peak discharge values, post flood analysis methods were used also to derive time of the raising flow, flood peak time, and rate of recession. Timing estimates were obtained based on eye witness's interviews and accounts. A standardized method for post-event analysis was used throughout the study. Estimates of flood peak for the earlier events were reviewed considering the original field notes, photographs, reports, and documentation, and conducting field visits to the flood locations [16]. Discharge data from stream gauges were obtained based on extrapolation of rating curves from smaller observed flows. The rating curves were checked to evaluate the degree of extrapolation required and to assess the quality of the final estimates [18].

Although great care was devoted to the various steps of discharge estimations, we should note that all the peak flood data should be regarded as affected by considerable uncertainty. An accuracy of 15-20 min has been reported for the timing estimates obtained by means of eyewitnesses interviews. The large percentage of discharge data obtained from post-event analysis underlines the importance of indirect discharge estimates in setting up catalogues of flash floods [9]. This is particularly the case for events which impact small catchment areas. Categorizes catchment areas according to the method used to derive the peak flood data (stream gauge versus post-event analysis). Discharge data from gauging stations generally concern catchments which are significantly larger than those for which estimates are obtained from post-event analysis. This is not an unexpected finding: larger scale flash floods events have higher probability to be recorded by stream flow measuring stations [12].

Whereas events with smaller spatial extent generally impact ungauged basins. An implication of this finding is that systematic survey of flash floods is particularly important in the region where these events are climatologically characterized by smaller spatial extent, such as in the sub-continental areas. Without systematic post-event analysis, it may be unlikely to develop reliable flash flood catalogues in these areas [11].

Focusing the river Kajoo for the purposes of water flow and gauged at two gauging station called Zirdan and Pirdan gauging stations though the catchment for Chabahar station is $750 \mathrm{~km}^{2}$ and the catchment area for the Gasrgand hydrometric station is $460 \mathrm{~km}^{2}$ however, the river network is a complex inter relationship of a historically. A conceptual approach that allowed some degree of perception of the hydrological processes to be expressed in mathematical form. The establishment and development of distributed monthly maximum flow analysis that account for the spatial variability of hydrological processes is appropriate to achieve river discharge in Balochistan, thus the different monthly maximum discharge $\mathrm{m}^{3} / \mathrm{s}$ are illustrated in Figures $(4,5,6,7$, and 8), which indicated various rate of flow for Sarbaz River during wet months [12] 
Thus peak discharges are shown during flash flood which is illustrated in figures number $(4,5,6,7$, and 8$)$.

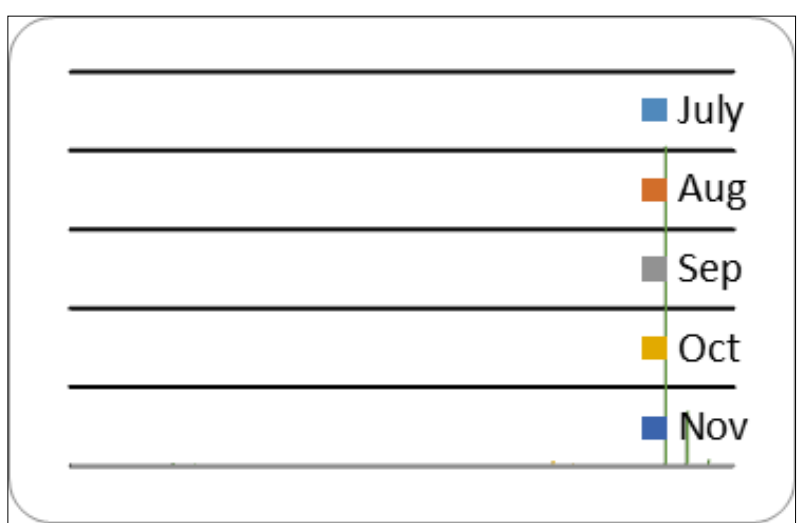

Figure 4 Monthly Maximum Rate of flow River Sarbaz Flash Flood During 2020

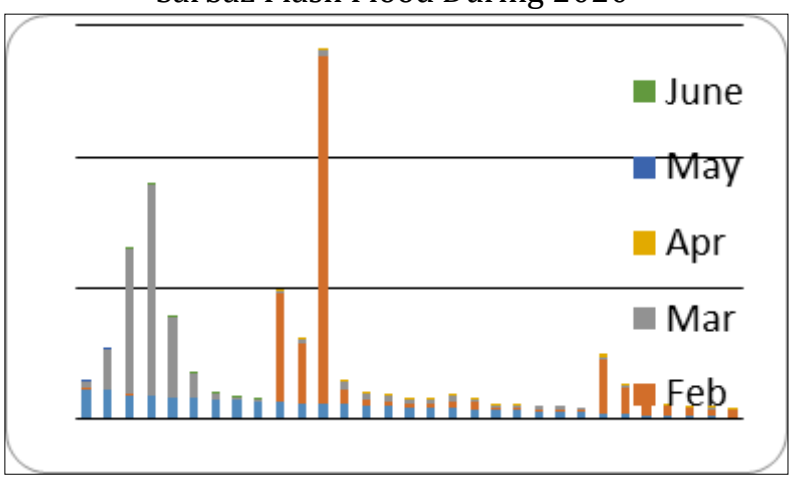

Figure 6 Monthly Maximum Rate of flow 2014 River Sarbaz Flash flood During 2014

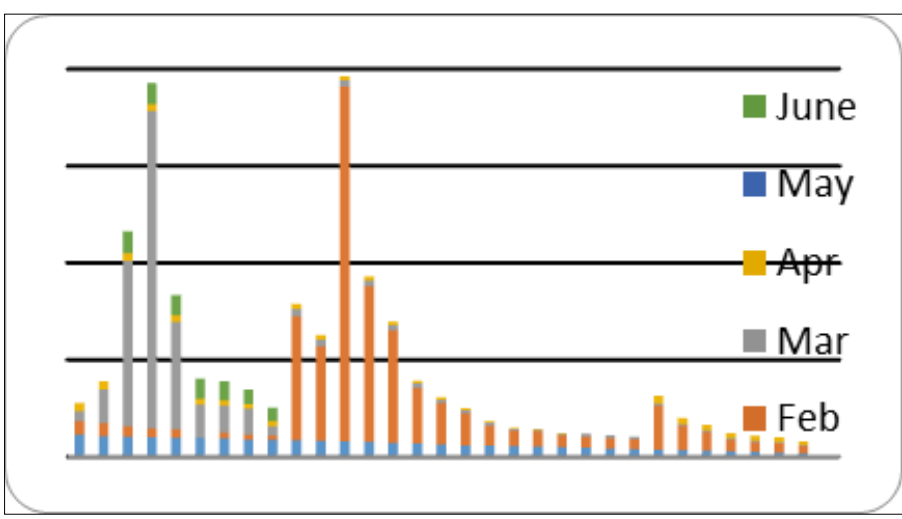

Figure 5 Monthly Maximum Discharge During Flash Flood Jan to June During flash flood from July to Dec. 2020

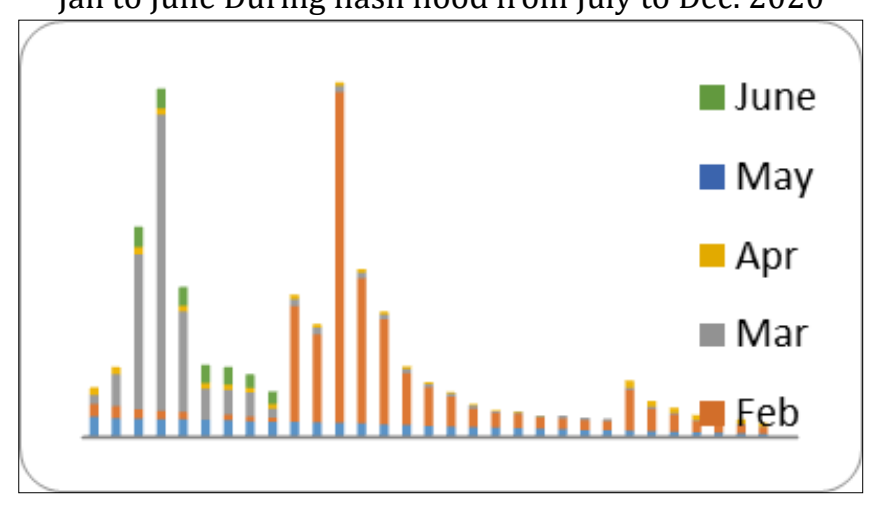

Figure 7 Monthly Maximum Discharge During Flash Flood Jan to June2014

Figure: River Kajoo monthly Maximum rate flow During flash flood from July to Dec. 2020.

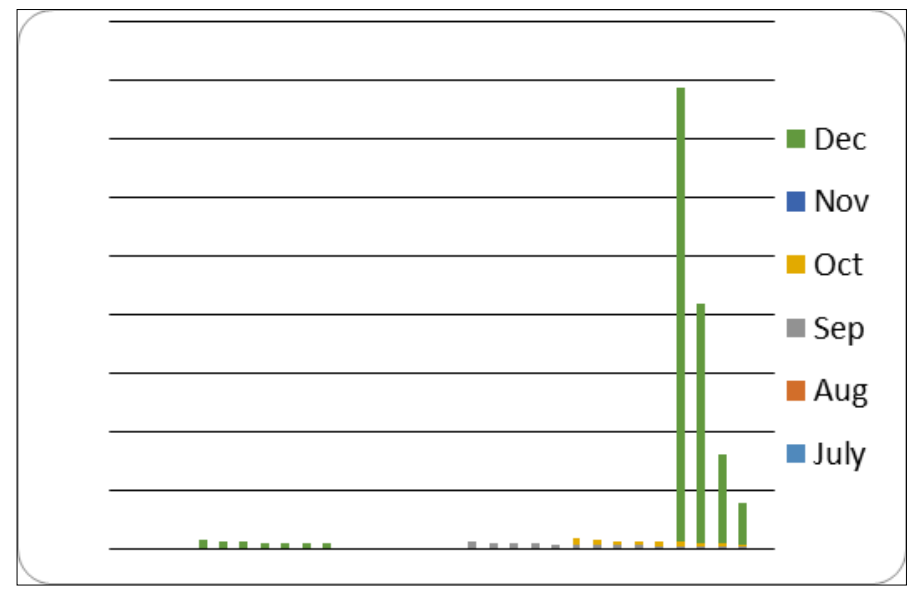

Figure 8 Kajoo River monthly Maximum Rate of Flow During flash flood from July to Dec. 2020

In the light of the storms and flood monthly maximum the calibration of river Sarbaz basically illustrated during month of December 2020 has been tested by computer the peak discharge was $4056 \mathrm{~m}_{3} / \mathrm{s}$, whereas during month of December 2014 was tested $3725 \mathrm{~m}^{3} / \mathrm{s}$, for the February 2020 was tested $256 \mathrm{~m}_{3} / \mathrm{s}$, for the March peak discharge has been tested by excel was $854 \mathrm{~m}_{3} / \mathrm{s}$ where as for the same river on the month of April suddenly rate of flow dropped to $6 \mathrm{~m} 3 / \mathrm{s}$ even though for other months during summer rate of flow for Sarbaz river is completely drought or nil discharge accordingly to the dry months when there is no rainfall in the all-region, this is the link between rainfall and storm characteristics 
and its effect on monthly maximum discharge have been dealt with in the past also the storms characteristics mainly considered were the storm pattern, might be speed and direction of rainstorm moving in the downstream direction produces a higher peak flow than storms moving upstream which can be concluded that storms moving at the same speed as the stream velocity have more impact on peak discharge than rapidly moving storms [13].

Therefore, for Kajoo river flow monthly maximum the calibration of river Kajoo basically illustrated during month of December 2020 has been tested by computer the peak discharge was $3879 \mathrm{~m}^{3} / \mathrm{s}$, whereas during month of December 2014 was tested $3025 \mathrm{~m}^{3} / \mathrm{s}$, for the February 2020 was tested $216 \mathrm{~m}^{3} / \mathrm{s}$, for the March peak discharge has been tested by excel was $706 \mathrm{~m}^{3} / \mathrm{s}$ where as for the same river on the month of April suddenly rate of flow dropped to $3 \mathrm{~m}^{3} / \mathrm{s}$ even though for other months during summer rate of flow for Kajoo river is completely drought or nil discharge accordingly to the dry months [5].

\section{Conclusion}

The research articles in this Special Issue addressed the challenges in flood management and proposed new methods, models and tools for understanding and improve flood resilience in the following four themes: hazard and risk analysis, flood behavior analysis, assessment frameworks and metrics, intervention strategies. Their contributions are discussed in the broader context of the field of flood management and help move towards integrate risk and resilience management.

Research challenges in achieving sustainable flood management remain in many aspects, including developing fast, accurate, high-resolution flood models, characterizing various uncertainties including deep uncertainty, developing integrated risk and resilience frameworks and effective metrics, understanding the relationships between flood risk and resilience, and developing adaptive management strategies with innovative technologies including machine learning technologies.

Since the floodway is an essential part of hydrologic and hydraulic studies of riverine flooding,in the Balochestan, requires one to be determined for developed communities using their approved computer programs has widely been used for flood risk and floodway regulation studies by many researchers. Because the floodway encroachment area is often used for human activities, it is a local government's interest to expand this area by minimizing the floodway footprint area that conveys the flood water without affecting the water surface elevation too much. Our objective is to minimize the floodway area while maintaining the surcharge and subcritical flow state reach-wide, both of which are required. Structural measures are related to physical provisions to reduce the risk of flooding. These include dams, dikes, storm surge barriers etc. Existence of enough storage to mitigate the impact of super floods is of paramount importance for flood protection.

\section{Compliance with ethical standards}

\section{Acknowledgments}

The authors are extremely grateful to the following companies and Organizations for their assistance with the collection of data: Water and Sanitation Organization, Water Resources Organization Chabahar and Agricultural Organisation. The authors would also like to express their great appreciation to Professor Mohammad Safar Mirjat and Dr. Abdolsamad Chandio for their valuable and constructive suggestions during the planning and development of this research work.

\section{References}

[1] Zhang T, Wang Y, Wang B, Tan S, Feng P. Nonstationary flood frequency analysis using univariate and bivariate time-varying models based on GAMLSS. Water. 2018; 10: 819.

[2] Saravi S, Kalawsky R, Joannou D, Rivas-Casado M, Fu G, Meng F. Use of artificial intelligence to improve resilience and preparedness against adverse flood events. Water. 2019; 11: 973.

[3] Fenner R, O’Donnell E, Sangaralingam A, Dawson D, Kapetas L, Krivtsov V, Ncube S, Vercruysse K. Achieving urban flood resilience in an uncertain future. Water. 2019; 11: 1082.

[4] Chen K, Leandro J. A conceptual time-varying flood resilience index for urban areas: Munich city. Water. 2019; 11: 830 . 
[5] Joannou D,Kalawsky R, Saravi S, Rivas-Casado M, Fu G, Meng F. A model-based engineering methodology and architecture for resilience in systems-of-systems: A case of water supply resilience to flooding. Water. 2019; 11: 496.

[6] Cho H, Yee T, Heo J. Automated floodway determination using particle swarm optimization. Water. 2018; 10: 1420 .

[7] Ahmad S. Water availability and future water requirements. Paper presented at the National Seminar on "Water Conservation, present situation and future strategy" organized by Ministry of Water and Power, Islamabad, Pakistan. May 2009.

[8] Archer DR,Fowler HJ. Using meteorological data to forecast seasonal runoff on the River Jhelum, Pakistan. J. of Hydrol. 2008; 361: 10-23.

[9] Gaurave K, Sinha R, Panda PK. The Indus flood of 2010 in Pakistan: a perspective analysis using remote sensing data. Nat. Hazards. 2011; 59: 1815-1826.

[10] Anukularmphai A. Interview by M. Wojciechowska-Shibuya. Maxims News Network. 2013.

[11] Anukularmphai A, MWojciechowska-Shibuya. The 2011 Floods in Thailand and the Role of IWRM. CRBOM Small Publications Series No. 46. Central Java, Indonesia: Center for River Basin Organizations and Management (CRBOM). July 2012.

[12] Borthwick A. Is the Lower Yellow River Sustainable? SOUE News (Society of Oxford University Engineers). 2005; 4: 4-8.

[13] Marshall M. Frozen Jet Stream Links Pakistan Floods, Russian Fires. New Scientist. 10 August 2010.

[14] Valipour M. Future of the area equipped for irrigation. Archives of Agronomy and Soil Science. 2014; 60: 16411660.

[15] Valipour M. Land use policy and agricultural water management of the previous half of century in Africa. Applied Water Science. 2014.

[16] Valipour M. Evolution of Irrigation-Equipped Areas as Share of Cultivated Areas. Irrigation and Drainage Systems Engineering. 2013; 2: e114.

[17] Valipour M. Necessity of Irrigated and Rainfed Agriculture in the World. Irrigation and Drainage Systems Engineering. 2013.

[18] Urban Flood Resilience Project. Key Project Outputs Report. 2019.

[19] Glenis V, Kutija V, Kilsby C. A fully hydrodynamic urban flood modelling system representing buildings, green space and interventions. Environ. Modell. Softw. 2018; 109: 272-292.

[20] Fenner R. Spatial evaluation of multiple benefits to encourage multi-functional design in blue green cities. Water. 2017; 9: 953.

[21] Ahilan S, Melville-Shreeve P, Kapelan Z, Butler D. The influence of household rainwater harvesting system design on water supply and stormwater management e_ciency. In New Trends in Urban Drainage Modelling; Mannina, G., Ed.; Springer: Cham, Swizerland. 2018; 369-374.

[22] Costa J, Fenner R, Kapetas L. A Screening Tool to Assess the Potential for Energy Recovery from the Discharge of StormwaterRuno_. In Proceedings of the Institution of Civil Engineers-Engineering Sustainability, London, UK, 20 December 2018; ICE Publishing: London, UK. 2018.

[23] Vercruysse K, Dawson D. Wright, N. Interoperability: A conceptual framework to bridge the gap between multifunctional and multi-system urban flood management. J. Flood Risk Manag. 2019.

[24] Everett G, Lamond J. Considering the value of community engagement for (co-) producing Blue-Green infrastructure. In Urban Water Systems \& Floods II. WIT Transactions on the Built Environment; WIT Press: Southampton, UK. 2018; 184: 1-14.

[25] O'Donnell E, Lamond J, Thorne C. Learning and Action Alliance framework to facilitate stakeholder collaboration and social learning in urban flood risk management. Environ. Sci. Policy. 2018; 80: 1-8. 